\title{
Post Analysis of Proficiency Test Samples Using Nuclear Magnetic Resonance Spectroscopy
}

\author{
Mamta Sharma \\ Directorate of International Cooperation, Defence R \& D Organization, Raja ji Marg, New Delhi, India \\ Email: reekana@rediffmail.com
}

How to cite this paper: Sharma, M. (2020) Post Analysis of Proficiency Test Samples Using Nuclear Magnetic Resonance Spectroscopy. Open Access Library Journal, 7: e6565.

https://doi.org/10.4236/oalib.1106565

Received: June 30, 2020

Accepted: July 28, 2020

Published: July 31, 2020

Copyright $\odot 2020$ by author(s) and Open Access Library Inc.

This work is licensed under the Creative Commons Attribution International License (CC BY 4.0).

http://creativecommons.org/licenses/by/4.0/ (c) (i) Open Access

\begin{abstract}
Paper describes the Post Nuclear Magnetic Resonance Spectroscopic analysis of proficiency test samples using Phosphorus NMR. In our study two-dimensional ${ }^{1} \mathrm{H}_{-}{ }^{31} \mathrm{P}$ NMR method was optimized effectively for identification of Chemical weapon convention related scheduled organophosphorus compounds in the environmental samples provided by OPCW during proficiency test, while second report is on post analysis of proficiency test sample, carried out to reexamine the samples to observe the missed organophosphorus compounds and to investigate the causes of missing of organophosphorus chemicals during analysis.
\end{abstract}

\section{Subject Areas}

Analytical Chemistry, Environmental Chemistry

\section{Keywords}

Phosphorus NMR, Organization for Prohibition of Chemical Weapons,

2-Dimensional Nuclear Magnetic Resonance, Chemical Weapon Convention,

Official Interlaboratory Proficiency Test

\section{Introduction}

Under CWC (Chemical Weapon Convention) treaty, entered into the force on $29^{\text {th }}$ April 1997, an international organization, "Organization for the Prohibition of Chemical Weapons" (OPCW) ensures implementation of CWC through a stringent verification regime. Till now OPCW has 193 member states [1]-[9]. In order to test the ability of laboratories and to designate the laboratories, OPCW conducts Inter laboratory "Official Proficiency Tests" (OPTs) twice in a year, to rule out any ambiguity during final testing in real scenario, to prove alleged use of CW agents. The designated laboratories have to maintain consistency in the 
OPTs to maintain their designation status. Approximately forty to forty-five laboratories from various countries have been participating regularly in these tests [5]-[14].

The most frequently used analytical techniques in OPTs, for the unambiguous identification of CWAs (Chemical Warfare Agents), their precursors and degradation products are, based on Nuclear magnetic resonance (NMR) spectroscopy, Gas Chromatography (GC) in combination with Mass Spectrometry (GC-MS) and/or tandem mass spectrometry (GC-MS/MS), Liquid Chromatography (LC) coupled with MS, and Infrared spectroscopy [4]-[9] [15]-[22]. GC-MS and Nuclear magnetic resonance (NMR) spectroscopy are the most frequently used techniques for analysis and identification of spiked chemicals in environmental samples as per evaluation reports of Official Proficiency Tests [1] [2] [3] [4] [21]-[32].

Since the CWC came into force, many efforts have been made to develop and improve methods for the detection and identification of CWAs, precursors and their degradation products for successful participation in proficiency tests [1] [2] [3] [9]-[33]. The successful participation in OPTs mainly depends on the availability of in-house spectral database of CWC related chemicals, efficient sample preparation, analytical skills of chemists, correct judgment and reporting skills and synthetic expertise [9] [10] [11] [12] [13] [15] [16] [17] [22]-[27] [31].

Nuclear magnetic resonance (NMR) spectroscopy is a valuable analytical technique for the identification of chemicals related to the CWC [32] [35]. More than $75 \%$ of the Scheduled chemicals are organophosphorus (OP) compounds, which are conveniently screened by ${ }^{31} \mathrm{P}\left\{{ }^{1} \mathrm{H}\right\}$ NMR experiment [9] [14]-[20] [32] [33] [34] [35] in mixtures. NMR gives complete information about the skeleton of the molecules by applying different NMR techniques. One-dimensional (1-D) proton, fluorine, and phosphorus NMR spectra $\left({ }^{1} \mathrm{H},{ }^{19} \mathrm{~F},{ }^{31} \mathrm{P}\left\{{ }^{1} \mathrm{H}\right\}\right.$, and ${ }^{31} \mathrm{P}$ spectra) are frequently recorded for analysis of test samples [22]-[35]. Chemicals are identified on the basis of matching of finger print spectra and chemical shifts of samples with spectra of reference chemicals. Normally 2-D NMR techniques are more suitable after screening of mixtures by 1-D NMR for complete structure elucidation of unknown chemicals by showing two and three bonds connectivity of phosphorus with alkyl groups [31]-[40]. Sometimes low concentration of chemical of interest in the presence of huge background may cause problems in NMR analysis. However, the structural specificity of NMR spectra, the capability for the observation of different nuclei, and the 2-D correlation experiments make NMR spectroscopy a valuable technique to be used in combination with other techniques for unambiguous identification of spiked chemicals listed in the Schedules of the CWC [1] [2] [3] [32]-[37]. The ${ }^{31} \mathrm{P}\left\{{ }^{1} \mathrm{H}\right\}$ and ${ }^{19} \mathrm{~F}$ NMR experiments are more useful than ${ }^{1} \mathrm{H}$ and used as screening tool to check the presence of organophosphorus (OP) compounds [32]-[37]. In some cases where concentration is sufficient the proton-coupled ${ }^{31} \mathrm{P}$ spectra, reveals more detailed structural information by showing splitting patterns, but use of this experiment 
is limited due to poor sensitivity [41]. Normally, the low sensitivity of NMR experiments are compensated by concentrating the samples and by running long-term experiments in OPTs (Official Proficiency Tests). In literature number of papers reveals successful use of ${ }^{31} \mathrm{P}$ NMR for analysis of OPTs samples [9] [20] [22] [23] [24] [31] [32] [33] [34] [41] [42]. Review on use of NMR techniques for toxic organophosphorus compound profiling, presents versatility of Nuclear Magnetic Resonance (NMR) spectroscopy in the analysis of toxic organophosphorus (OP) compounds [42]. Two-dimensional ${ }^{1} \mathrm{H}-{ }^{31} \mathrm{P}$ Fast-HMQC (Heteronuclear multiple quantum correlation) was optimized for rapid detection of OP compounds at low concentration [34]. The advantage of NMR detection is that it is free from any extra sample preparation, memory effect and cross contamination [32]-[40]. Therefore in this paper we emphasized the importance of NMR based techniques and investigated the possible reasons of missing the compounds during test in water and organic sample of $19^{\text {th }}$ proficiency test using NMR only and performed the optimization of 2D NMR technique using vacuum pump oil sample of $17^{\text {th }}$ proficiency test sample. The effect of concentration and $\mathrm{pH}$ on phosphorus chemical shift is also observed. It is also realized that when molecules are having more than two stereogenic centers then identification in NMR becomes difficult at low concentration. During analysis of $19^{\text {th }}$ proficiency test samples we missed OP compounds. Therefore it was planned to reexamine the samples after the test, to find out the reason of failure. The experience gained from the exercises could be useful in decipher the structure of unknown OP compounds during OPTs and helpful in obtaining the required designation.

\section{Experimental Part}

Two 400-MHz Bruker, Avance and DPX NMR spectrometers were used for the detection of Scheduled chemicals in environmental samples. Temperature was kept 296 to $300 \mathrm{~K}$ in all the experiments. Computer operating systems UNIX, Xwin NMR 2.3 and Top spin 1.3 were used. The direct observation BBO probe head (broad band observe) was used for 1-D and 2-D HSQC experiments on ${ }^{1} \mathrm{H}$ and ${ }^{31} \mathrm{P}\left\{{ }^{1} \mathrm{H}\right\}$ nuclei with proton broadband (composite pulse) decoupling. ${ }^{19} \mathrm{~F}\left\{{ }^{1} \mathrm{H}\right\}$ Nucleus was observed by the use of Fluorine selective $5 \mathrm{~mm}$ probe head using zgpg pulse sequence, sweep width $37,664.78 \mathrm{~Hz}$, acquisition time $3.48 \mathrm{sec}$, delay 1 sec., NMR frequency $376.474 \mathrm{MHz}$, and pulse angle $9.40 \mu \mathrm{sec}$. For ${ }^{31} \mathrm{P}$ nucleus, sweep width 43,859.64 swh, acquisition time $2.98 \mathrm{sec}$, delay $2 \mathrm{sec}$, td \& si $128 \mathrm{~K}$ and Magnet frequency was tuned at $161.9755 \mathrm{MHz} .{ }^{31} \mathrm{P}\left\{{ }^{1} \mathrm{H}\right\},{ }^{1} \mathrm{H}$ and ${ }^{19} \mathrm{~F}$ $\left\{{ }^{1} \mathrm{H}\right\} \mathrm{NMR}$ spectra were recorded keeping range -150 to $150 \mathrm{ppm},-0.5$ to 14 ppm and -100 to $20 \mathrm{ppm}$ respectively. FID (Free Induction Decay) was Fourier transformed after application of an exponential window function. Baseline correction was done to improve the resolution and signal height of very small intensity resonances.

The sensitivity, resolution checking and pulse calibration was carried out for each nucleus separately. Separate tuning of the probe head for each sample and 
nucleus was adjusted to obtain the optimum sensitivity. Accurate homogeneity adjustment was done by doing shimming, in order to achieve the narrowest lines and pure line shape. Spectroscopic grade E-Merck solvents; Deuterium oxide $\left(\mathrm{D}_{2} \mathrm{O}\right)$, Chloroform-d1 $\left(\mathrm{CDCl}_{3}\right)$, of $>99.9 \%$ deuteration were used for NMR samples analysis. Chemical shift $(\delta)$ references for calibration of the spectrum scale were used externally $85 \% \mathrm{H}_{3} \mathrm{PO}_{4}$ at $0.00 \mathrm{ppm}$ for ${ }^{31} \mathrm{P}, \mathrm{CF}_{3} \mathrm{COOH}$ for ${ }^{19} \mathrm{~F}$ at $-76.50 \mathrm{ppm}$. An internal chemical shift reference for ${ }^{1} \mathrm{H}$, tetramethylsilane TMS in $\mathrm{CDCl}_{3}$ and 3-(trimethylsilyl) -3, 3, 2, 2-tetradeuteropropionic acid sodium salt (TSPA-d4) in $\mathrm{D}_{2} \mathrm{O}$ at $0.00 \mathrm{ppm}$ was used. $5 \mathrm{~mm}$ Wilmad Royal Imperial NMR tubes were used for analysis and Tubes were cleaned repeatedly with distilled water followed by acetone, and dried in oven (at $1000^{\circ} \mathrm{C}$ ). Initially samples were analyzed as such without doing any extraction, to check the presence of any volatile compounds by NMR. Sample preparation and analysis were done as per recommended procedure (ROP) of OPCW for test [43].

Three samples (Vacuum pump oil, Organic waste and Soil) along with their corresponding blank samples were received for analysis with proper laboratory coding in Seventeenth OPCW Proficiency Test. In order to analyze the vacuum pump oil sample, $2 \mathrm{ml}$ of sample was extracted with methanol $(3 \times 800 \mu \mathrm{l})$, methanol was evaporated by Nitrogen purging up to dryness in one sample and 700 $\mu \mathrm{D}_{2} \mathrm{O}$ was added while in second sample evaporation was done up to $400 \mu \mathrm{l}$ and $300 \mu \mathrm{l} \mathrm{D} 2 \mathrm{O}$ was added for ${ }^{31} \mathrm{P}\left\{{ }^{1} \mathrm{H}\right\} \mathrm{NMR}$ analysis. This was done to observe the volatile chemicals in samples, but in both the cases same results were obtained. The organic waste sample $(500 \mu \mathrm{l})$ was taken as such in a NMR tube and $200 \mu \mathrm{l}$ $\mathrm{CDCl}_{3}$ was added to screen the presence of organophosphorus (OP) compound by ${ }^{31} \mathrm{P}\left\{{ }^{1} \mathrm{H}\right\}$. Organic sample of $19^{\text {th }}$ OPTs was prepared in the similar manner. The soil sample $(500 \mathrm{mg})$ was extracted with $3 \times 500 \mu \mathrm{l}$ methanol and extracts were combined and centrifuged as per ROP (Recommended Operating Procedure) [33]. The methanol was removed by nitrogen stream until the volume of $200 \mu \mathrm{l}$ remains. It was make-up up to $700 \mu \mathrm{l}$ by addition of $500 \mu \mathrm{D}_{2} \mathrm{O}$ and analyzed by ${ }^{31} \mathrm{P}\left\{{ }^{1} \mathrm{H}\right\}$ NMR. The same treatment was given to their corresponding three blank samples. In the nineteenth OPTs, OPCW forwarded three samples; one organic liquid and two water samples. The spiking level of all the chemicals was $6-20 \mu \mathrm{g} / \mathrm{ml}$ as per scenario provided by the OPCW. All the samples were stored in deep freezer for two hours so that volatile compound, should get condensed in the sample.

Both the water samples and corresponding blank samples, $500 \mu \mathrm{l}$ were taken in a NMR tube and mixed with $200 \mu \mathrm{D}_{2} \mathrm{O}$ and shaken for one minute on vortex shaker for homogenous mixing.

\section{Results and Discussion}

Here post NMR analysis of samples of seventeenth and nineteenth OPCW Proficiency tests are being described in detail. In the vacuum pump oil sample of $17^{\text {th }}$ OPTs only one OP Compound, Dimethyl methylphosphonate (DMMP) was found and 2D NMR method was optimized for its trace level detection. While in 
Organic sample of $19^{\text {th }}$ OPTs only three OP compounds 4-methylpentyl methylphosphonofluoridate (correctly identified), Pinacolyl methylphosphonic acid (wrongly reported), tetraethyl ethylenediphosphate (false identification) out of four were identified and one compound failed to identify. One OP Compound in Water sample 1, also remained unanswered while other three isomers of O-hexyl methylphosphonate were identified correctly. In this paper, in post analysis we concentrated only on three samples; vacuum pump oil ( $17^{\text {th }}$ test), organic and water 1 samples ( $19^{\text {th }}$ test).

\subsection{NMR Results of Seventeenth Proficiency Test (Vacuum Pump Oil)}

${ }^{31} \mathrm{P}\left\{{ }^{1} \mathrm{H}\right\} \mathrm{NMR}$ analysis of sample showed no phosphorus signal in soil and organic samples except one at $\delta 38.401 \mathrm{ppm}$ (Figure 1) in vacuum pump oil sample. The concentrated extracted sample of vacuum pump oil was analyzed by 2D NMR technique for assigning the complete skeleton of the compound. Finally, the structure of spiked compound was assigned as dimethyl methylphosphonate (DMMP) with the help of 2D NMR analysis. The methyl groups of $\mathrm{CH}_{3}-\mathrm{P}=\mathrm{O}$ and $\mathrm{CH}_{3} \mathrm{O}-\mathrm{P}=\mathrm{O}$ groups of DMMP showed connectivity with phosphorus signal appeared at $38.40 \mathrm{ppm}$ with doublet signals at $1.49 \mathrm{ppm}$ $\left({ }^{2} \mathrm{~J}_{\mathrm{P}-\mathrm{H}}=17.56 \mathrm{~Hz}\right)$ and at $3.61 \mathrm{ppm}\left({ }^{3} \mathrm{~J}_{\mathrm{P}-\mathrm{H}}=10.84 \mathrm{~Hz}\right)$ respectively of ${ }^{1} \mathrm{H} \mathrm{NMR}$ which is shown in Figure 2, 2D ${ }^{1} \mathrm{H}^{-31} \mathrm{P}\left\{{ }^{1} \mathrm{H}\right\}$ HSQC (Heteronuclear Single Quantum Correlation) spectrum. 2D HSQC NMR of reference sample (Figure 4) along with $1 \mathrm{D}{ }^{1} \mathrm{H}$ and ${ }^{31} \mathrm{P}\left\{{ }^{1} \mathrm{H}\right\}$ is shown in Figure 3 and matched with spectra of spiked sample (Figure 2).

\subsection{NMR Results of Nineteenth OPCW Official Proficiency Test}

\section{Organic Sample}

Eight signals were observed in the range of 33.107 to $-18.040 \mathrm{ppm}$ in organic sample after the accumulation of 17,720 scans (Figure 5). Three signals out of eight appearing at $0.891 \mathrm{ppm},-1.771 \mathrm{ppm}$ and $-18.040 \mathrm{ppm}$ may arose from phosphate type of compounds as phosphates appear in this range in ${ }^{31} \mathrm{P}$ NMR and later reconfirmed by Mass Spectrometry. Since the phosphates are not relevant to CWC, these are not discussed here. The remaining five signals appeared in the range of CWC related compounds.

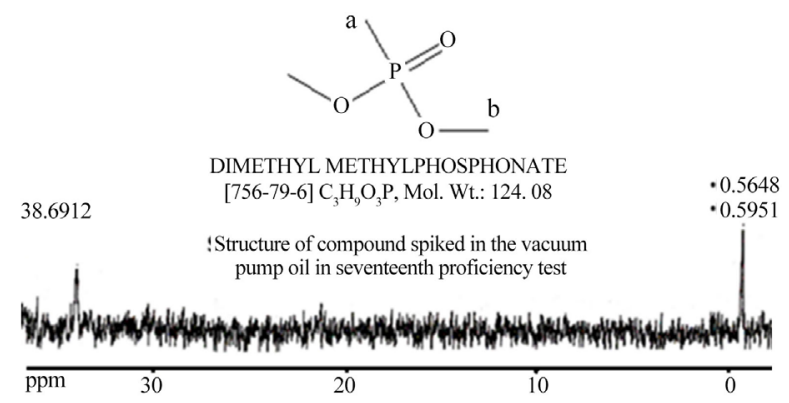

Figure 1. 1D ${ }^{31} \mathrm{P}\left\{{ }^{1} \mathrm{H}\right\}$ NMR Spectrum of Vacuum pump oil Sample in $\mathrm{D}_{2} \mathrm{O}$ Solvent. 


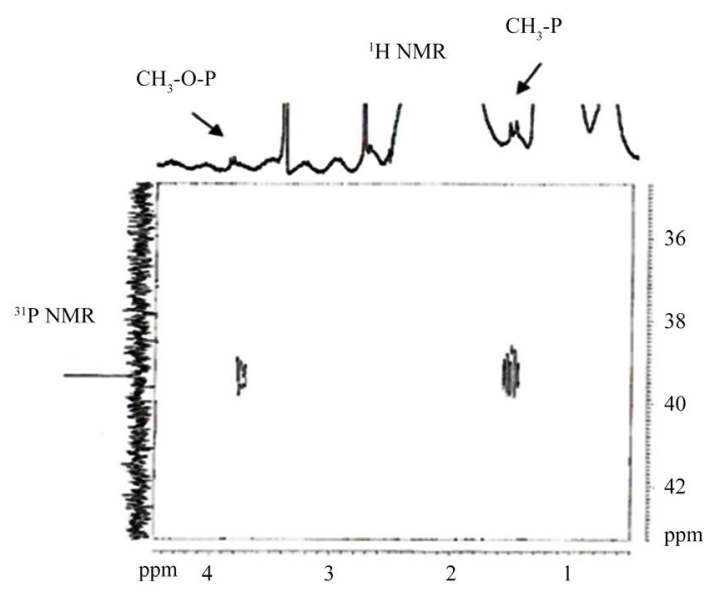

Figure 2. 2D-HSQC ${ }^{1} \mathrm{H}-{ }^{31} \mathrm{P}$ NMR Spectrum of oil Sample showing cross peaks for Dimethyl methylphosphonate (DMMP).

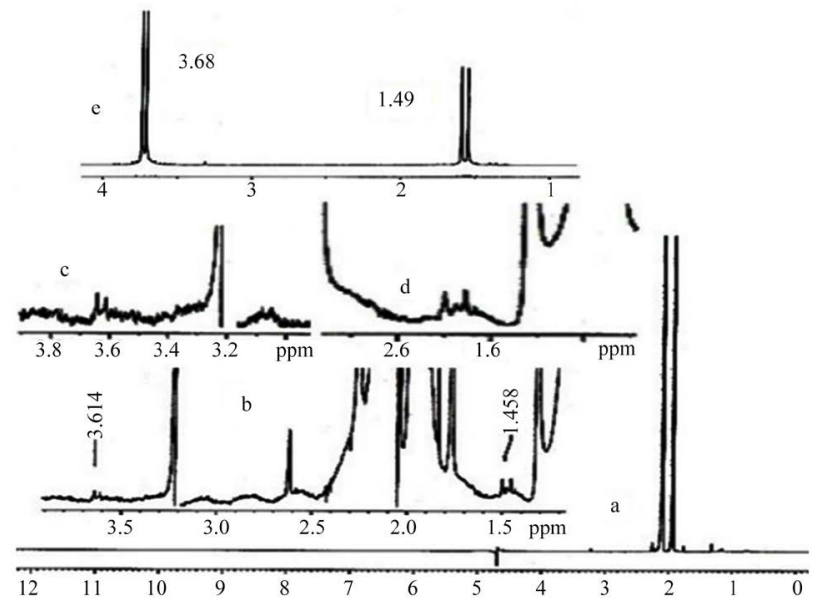

Figure 3. ${ }^{1} \mathrm{H}$ Spectrum of Vacuum pump oil Sample with water Suppression (a), expanded region of ${ }^{1} \mathrm{H}$ Spectrum showing $1 \mathrm{ppm}$ to $4 \mathrm{ppm}$ range of Chemical Shift (b). Expanded region of Spectrum showing doublet of $\mathrm{CH}_{3} \mathrm{O}-\mathrm{P}$ group at $3.61 \mathrm{ppm}$ (c), and of $\mathrm{CH}_{3}-\mathrm{P}$ group at $1.4 \mathrm{ppm}(\mathrm{d}) .{ }^{1} \mathrm{H}$ NMR Spectrum of Reference Compound Showing doublets for $\mathrm{CH}_{3} \mathrm{O}-\mathrm{P}$ and $\mathrm{CH}_{3}-\mathrm{P}$ groups of Dimethyl methylphosphonate (e).

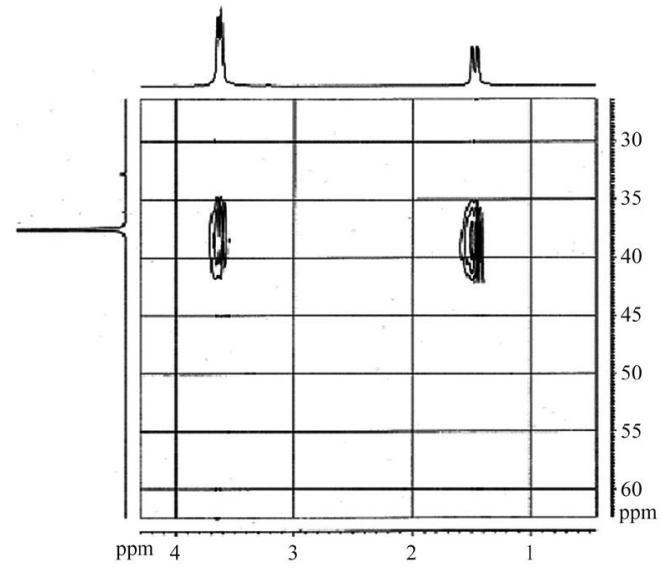

Figure 4. 2D-HSQC ${ }^{1} \mathrm{H}^{31} \mathrm{P}$ NMR Spectrum of Reference Chemical Showing cross peaks for Dimethyl methylphosphonate. 


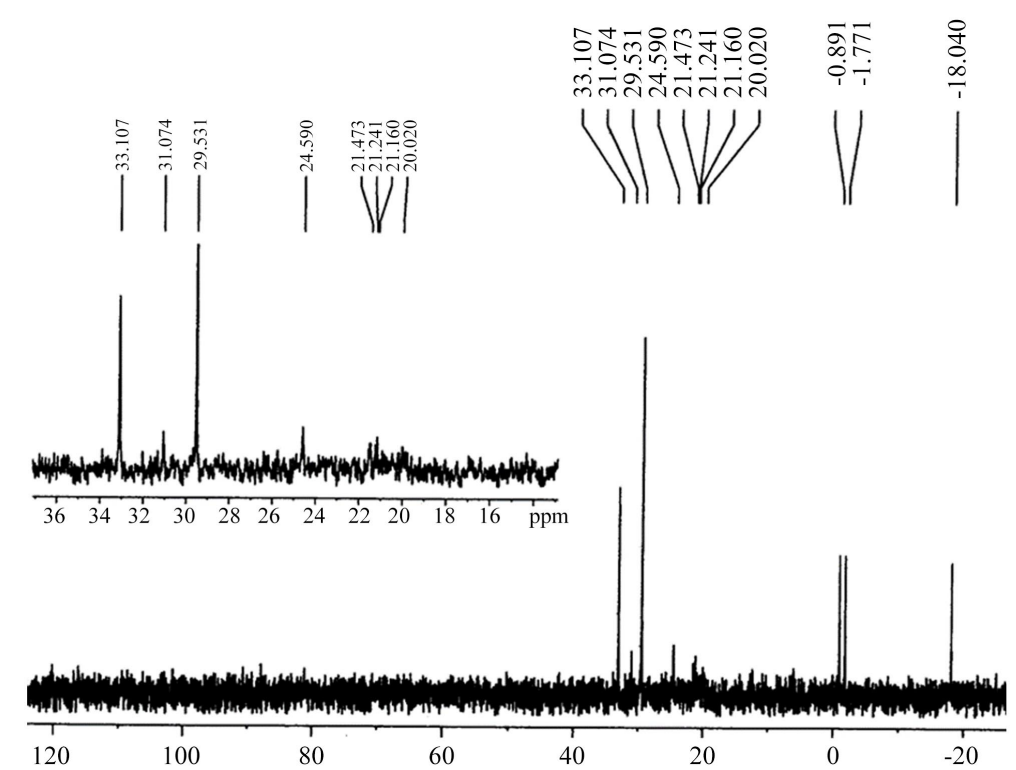

Figure 5. ${ }^{31} \mathrm{P}\left\{{ }^{1} \mathrm{H}\right\}$ NMR Spectrum of Organic Liquid sample with expansion in $\mathrm{CDCl}_{3}$ showing Phosphorus Signals ranging from $33.10 \mathrm{ppm}$ to $-18 \mathrm{ppm}$.

Among the five signals, $(33.107,31.074,29.531,24.590$, and multiple signals in the range of 21.473 to 20.020), two intense signals were of equal height, and remaining three were having good intensity. The two intense signals at 31.107 and $24.590 \mathrm{ppm}$ were accounted as fluoridate doublet. In order to check our assumption, the $\delta$ difference between all the peaks was calculated in $\mathrm{Hz}$. The difference of $1050 \mathrm{~Hz}$ was found only for two signals appeared at $31.074 \mathrm{ppm}$ and $24.590 \mathrm{ppm}$, which is in the range of coupling value of phosphorus with fluorine. The same sample was analyzed by ${ }^{19} \mathrm{~F}$ NMR to confirm the presence of fluorine containing organophosphorus compound. It showed two signals at -59.28 and $-62.06 \mathrm{ppm}$ due to coupling of fluorine with phosphorus (Figure 6). There is pronounced effect of directly attached alkyl group to phosphorus, on P-F coupling constant in fluorine containing OP compounds. The coupling constant for groups $\mathrm{CH}_{3}-\mathrm{P}(\mathrm{O})-\mathrm{F}, \mathrm{C}_{2} \mathrm{H}_{5}-\mathrm{P}(\mathrm{O})-\mathrm{F}$, isopropyl- $\mathrm{P}(\mathrm{O})-\mathrm{F}$ and n-propyl-P(O)-F is $\sim 1048 \mathrm{~Hz}, \sim 1070 \mathrm{~Hz}, \sim 1087 \mathrm{~Hz}$ and $\sim 1067 \mathrm{~Hz}$ respectively. From this data it was inferred that the alkyl group directly attached to phosphorus is methyl $\left({ }^{1} \mathrm{~J}_{\mathrm{P}-\mathrm{F}}=1050 \mathrm{~Hz}\right.$ ) (on the basis of P-F coupling constant) which is mandatory for reporting also. So prediction of attached alkyl group to phosphorus could be made on the basis of coupling constant value $\left(J_{\mathrm{P}-\mathrm{F}}\right)$ values, in fluoridates. 4-methylpentyl group of this OP compound confirmed by Mass spectrometry. The structure of this compounds was therefore, assigned as 4-methylpentyl methylphosphonofluoridate after perfect matching with reference sample (Figure 6) under the identical experimental conditions. ${ }^{19} \mathrm{~F}$ and ${ }^{31} \mathrm{P}\{\mathrm{H}\}$ NMR of 4-methylpentyl methylphosphonofluoridate presenting matching of chemical shift values with reference chemical, is shown in Figure 6. One compound at $29.531 \mathrm{ppm}$ was identified as Pinacolyl methylphosphonic acid with the help of Mass and phosphorus signal $\delta$, matched with reference at $29.531 \mathrm{ppm}$. 


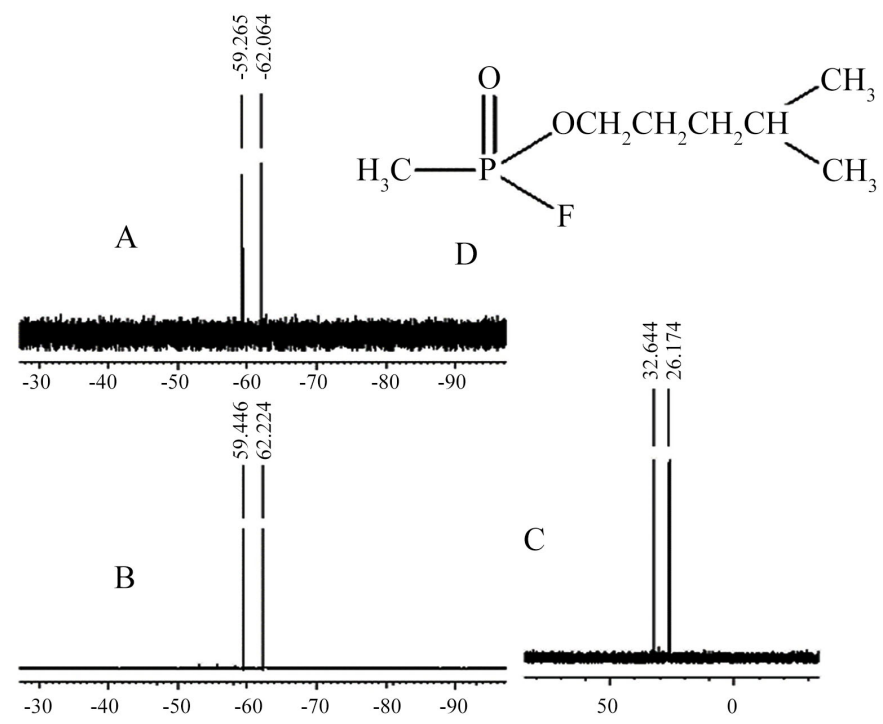

Figure 6. ${ }^{19} \mathrm{~F}\left\{{ }^{1} \mathrm{H}\right\}$ NMR Spectra of Organic Sample (A), Reference Sample (B), showing matching of Chemical shifts. ${ }^{31} \mathrm{P}\left\{{ }^{1} \mathrm{H}\right\}$ Spectrum of Reference Sample (C), and Structure of Spiked Chemical 4-methylpentyl methylphosphonofluoridate (D).

The multiple signals ranging from 21 to $20 \mathrm{ppm}$ were assumed that these may be because of several diastereomers of one of the spiked compounds or due to presence of more than one compound or degraded product of any OP compound. No NMR and Mass data of this chemical was available in any of the spectral library of OCAD or NIST MS-library [44] and in-housed developed NMR library available with us at that time, hence this compound could not be identified. Hence multiple signals in the range 21 to $20 \mathrm{ppm}$ remained unanswered (Figure 5). Later this molecule was reported as Dipinacolyl dimethylpyrophosphonate by OPCW [45]. So in this test one compound was missed in reporting and one compound was reported wrongly at $33.107 \mathrm{ppm}$ as tetraethyl ethylenediphosphate. OPCW later reported [45] this molecule as new cyclic phosphonate O,O-1,3-trimethylene isopropylphosphonate.

\section{Water sample 1}

The $\mathrm{pH}$ of the water sample (actual and blank) was found neutral and it was screened as such without any sample preparation, by ${ }^{31} \mathrm{P}\left\{{ }^{1} \mathrm{H}\right\}$ NMR along with blank sample, in order to avoid the loss of volatile compounds. Results showed that there is no signal in the blank sample. However, the water sample showed four signals at $26.607 \mathrm{ppm}, 25.289 \mathrm{ppm}, 25.138 \mathrm{ppm}$ and $20.88 \mathrm{ppm}$ in ${ }^{31} \mathrm{P} \mathrm{NMR}$ $\left\{{ }^{1} \mathrm{H}\right\}$ analysis after 11,080 scans as shown in the Figure 7(A). The chemical shift values of these four compounds (26.607 ppm, $25.289 \mathrm{ppm}, 25.138 \mathrm{ppm}$ and $20.88 \mathrm{ppm}$ ) showed that these compounds have $\mathrm{P}=\mathrm{O}$ functionality (as $\mathrm{P}=\mathrm{O}$ containing OP compounds fall in this range), which might have arisen either from alkyl phosphonic acids or from O-alkyl alkylphosphonic acids. Esters of phosphorus related to scheduled chemicals do not fall in this range in water. These show chemical shift values around 32 to $38 \mathrm{ppm}$ in water. In order to confirm whether these signals have arisen from monoacids or diacids; sample was derivatised 


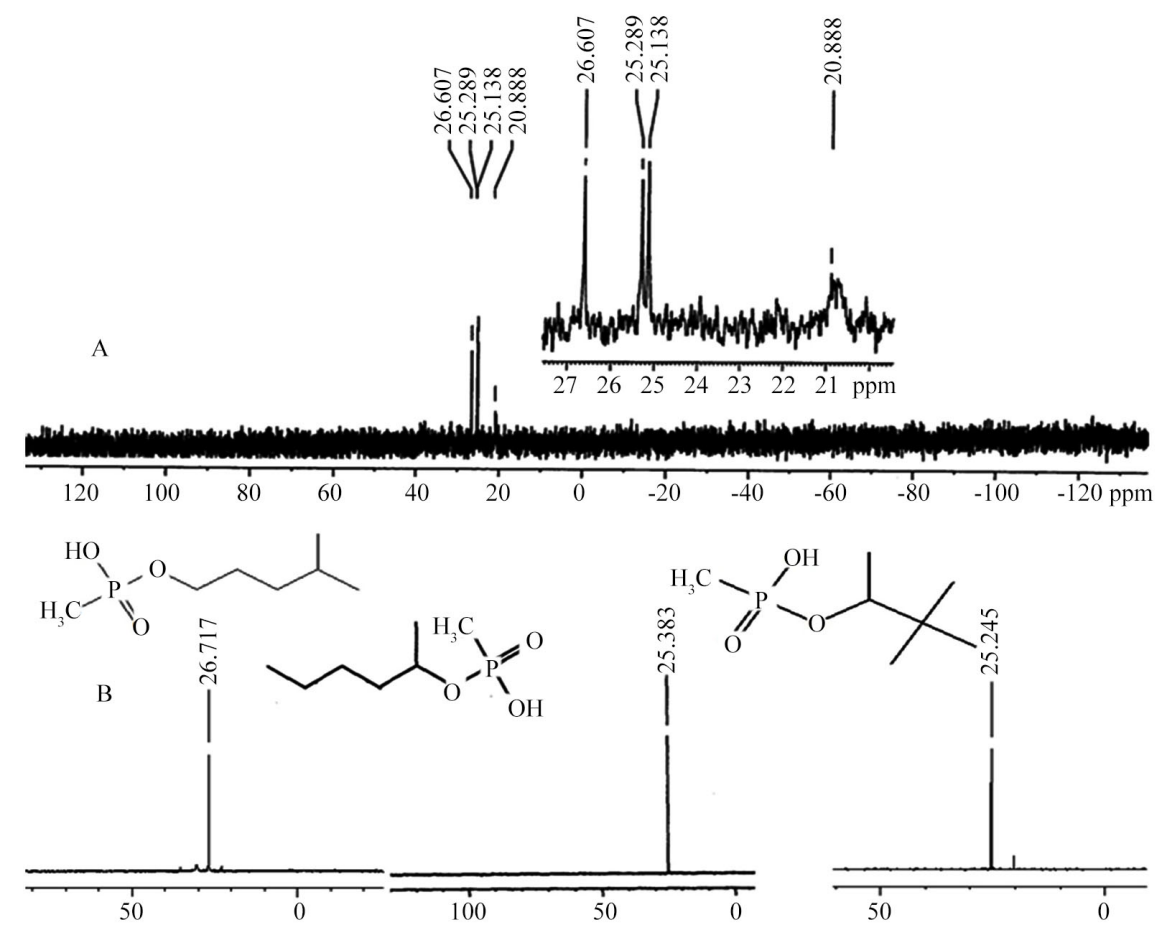

Figure 7. ${ }^{31} \mathrm{P}\left\{{ }^{1} \mathrm{H}\right\}$ NMR Spectra obtained from analysis of: Water 1 Sample (A), Reference Chemicals (B), in $\mathrm{D}_{2} \mathrm{O}$.

with diazomethane to make their methyl derivatives. The derivatised sample was analyzed by NMR followed by GC/MS and confirmed presence of monoacids. The nature of P-C linkage is confirmed by 2-D NMR experiment. The result of 2D HSQC ${ }^{1} \mathrm{H}^{-31} \mathrm{P}\left\{{ }^{1} \mathrm{H}\right)$ NMR analysis showed connectivity of three ${ }^{31} \mathrm{P}$ signals (range 25 to $26 \mathrm{ppm}$ ) with methyl doublet signal in ${ }^{1} \mathrm{H}$ NMR at $\sim 1.50 \mathrm{ppm}, \sim^{2} \mathrm{~J}_{\mathrm{P}-\mathrm{H}}$ $=16 \mathrm{~Hz}$, for three compounds and confirmed that these three chemicals have $-\mathrm{CH}_{3}$ group attached to phosphorus atom in their structure directly and later these were found isomers as the molecular weight for all the three compounds was same, in Mass analysis ( $180 \mathrm{mw})$. Thus it was confirmed that all the three compounds have the structure of alkyl methylphosphonic acids. Furthermore, by getting the clue of molecular weight of the compounds from GC/MS, it was easy to assign the P-OR group of the structures and it was assigned as O-hexyl group. Therefore, to assign the chain of $\mathrm{P}_{-} \mathrm{OC}_{6} \mathrm{H}_{13}$ group in their structures various derivatives of hexyl methylphosphonic acid were synthesized by using different isomers of $\mathrm{n}$-hexanol. The $\mathrm{pH}$ in all the analysis was kept neutral. Thus, they were identified as positional isomers of hexyl methylphosphonate after matching their signature with synthesized reference samples. Probably, because of the resemblance in the structures of positional isomers their chemical shift values were found very close to each other. However, the change in concentration and $\mathrm{pH}$ were critical factors for matching their spectra with reference samples. In order to confirm the skeleton of spiked compounds, 2D HSQC NMR experiment was performed with the concentrated sample and results reconfirmed the presence of both $\mathrm{P}-\mathrm{CH}_{3}, \mathrm{P}-\mathrm{OCH}_{2}$, and P-OCH groups. After, assign- 
ing the structures for the three signals it was necessary to have some meaningful conclusion about the fourth signal of $20.88 \mathrm{ppm}$. But we were failed in identifying this compound. This was assumed that this hump may be due to methylphosphonic acid (MPA). But chemical shift value of this signal did not match with any of the spectral data of MPA available in library at neutral $\mathrm{pH}$. Water 1 sample was analyzed in $\mathrm{CDCl}_{3}$ also, after evaporation of water, to analyse the hump signal of $20 \mathrm{ppm}$ (Figure 7(A)), with the idea that due to less solubility chemical is not coming properly in water solvent, but due to low concentration during extraction, it was totally removed from the mixture and no signal was observed for this chemical in organic medium (only three signals found). Then it was also assumed that this hump is not due to OP chemical, some artifact is present in the sample or it may be the result of bad shimming or some field variation in long acquisition time. Unfortunately, later, it was interpreted as signal of methylphosphonic acid in posttest analysis.

Assignment of closely appeared signals at $\delta 26.607,25.289$ and 25.138 ppm

The assignment of closely lying signals of OP compounds was done by standard addition method (adding reference compounds in mixture one by one). First $10 \mu \mathrm{l}$ sample of each reference compound (three isomers of hexyl methylphosphonic acid) was taken in the NMR tubes separately. Each sample was prepared by addition of $650 \mu \mathrm{D}_{2} \mathrm{O}$ and $\mathrm{pH}$ maintained neutral. Their ${ }^{31} \mathrm{P}$ NMR spectra were recorded and chemical shift values were observed, they were all showing different ppm values as shown in above heading and closely related with the spiked sample. As we know that there is an effect of $\mathrm{pH}$, concentration and presence of other chemical on the chemical shift and this may cause variation of $\sim 1$ to $2 \mathrm{ppm}$; to study the effect of interference on the chemical shift value, addition of all the three isomers was done one by one in the same NMR tube so that the effect of three isomers on each other's chemical shift values can be observed. First $10 \mu \mathrm{l}$ pinacolyl methylphosphonic acid was taken in NMR tube in $\mathrm{D}_{2} \mathrm{O}$ and $\mathrm{pH}$ was maintained at neutral by adding $10 \%$ alkaline $\mathrm{D}_{2} \mathrm{O}$ solution. It showed signal at $25.138 \mathrm{ppm}$, now $10 \mu \mathrm{l}$ 1-methylpentylmethylphosphonic acid was added (prepared in neutral $\mathrm{pH}$ ) in the same solution and NMR Spectrum was recorded. It showed an additional signal at $25.289 \mathrm{ppm}$. Finally, $10 \mu \mathrm{l}$ of 4-methylpentyl methylphosphonic acid was added in the same NMR tube by maintaining neutral $\mathrm{pH}$. It showed one more additional peak at $26.607 \mathrm{ppm}$ along with two signals of previously added chemicals. There was no variation in their chemical shift values although they were close lying after addition of chemicals in the same NMR sample tube as addition was done at low concentration and at neutral $\mathrm{pH}$. At low concentration and at neutral $\mathrm{pH}$ chemical shifts values were exactly matched with the reference chemicals and this is the important criteria of identifying the chemicals in the spiked tests samples by NMR. Further structures of chemicals were re-confirmed by doing the standard addition of reference sample (diluted compounds) in standard test sample (standard 
addition technique). In the standard addition, the intensity of a particular signal was increased after addition of a known reference chemical in test sample, which assigned the structure of a particular compound. After confirming the structure of one of the three compounds, remaining two compounds were also confirmed by applying same technique. The $\delta$ value of spiked chemicals was matched with reference chemicals as shown in Figure 7(B) for the pinacolyl methylphosphonic acid (25.138 ppm), 1-methylpentyl methylphosphonic acid (25.289 ppm), and 4-methylpentyl methylphosphonic acid (26.607 ppm).

\section{Water sample 2}

The water sample 2 was analyzed like water sample 1 . It indicated the presence of one organophosphorus compound by showing only one signal in ${ }^{31} \mathrm{P}$ NMR analysis. Corresponding blank sample did not show any signal. Second water sample (W-2) showed the presence of one signal at $30.145 \mathrm{ppm}$ in ${ }^{31} \mathrm{P}\left\{{ }^{1} \mathrm{H}\right\}$ NMR analysis even after concentrating the sample (Figure 8(A)). The chemical shift value at neutral $\mathrm{pH}$ matched with reference compound isopropylphosphonic acid as shown in Figure 8(B). Proton coupled $\left({ }^{31} \mathrm{P}\right)$ NMR of concentrated W-2 sample showed the coupling of phosphorus with protons of alkyl group and showed complex multiplicity of eight peaks [41]. On matching the spectrum with coupled library spectrum, the structure of isopropylphosphonic acid in second water sample was confirmed. Further optimized 2D HSQC NMR technique was used for confirmation of structure of spiked chemical (Figure 9). The cross peaks at $30 \mathrm{ppm}$ of phosphorus signal showed bond connectivity with methyl at $1.04 \mathrm{ppm}$ and methine proton at $1.57 \mathrm{ppm}$ of isopropyl group and confirmed the structure.

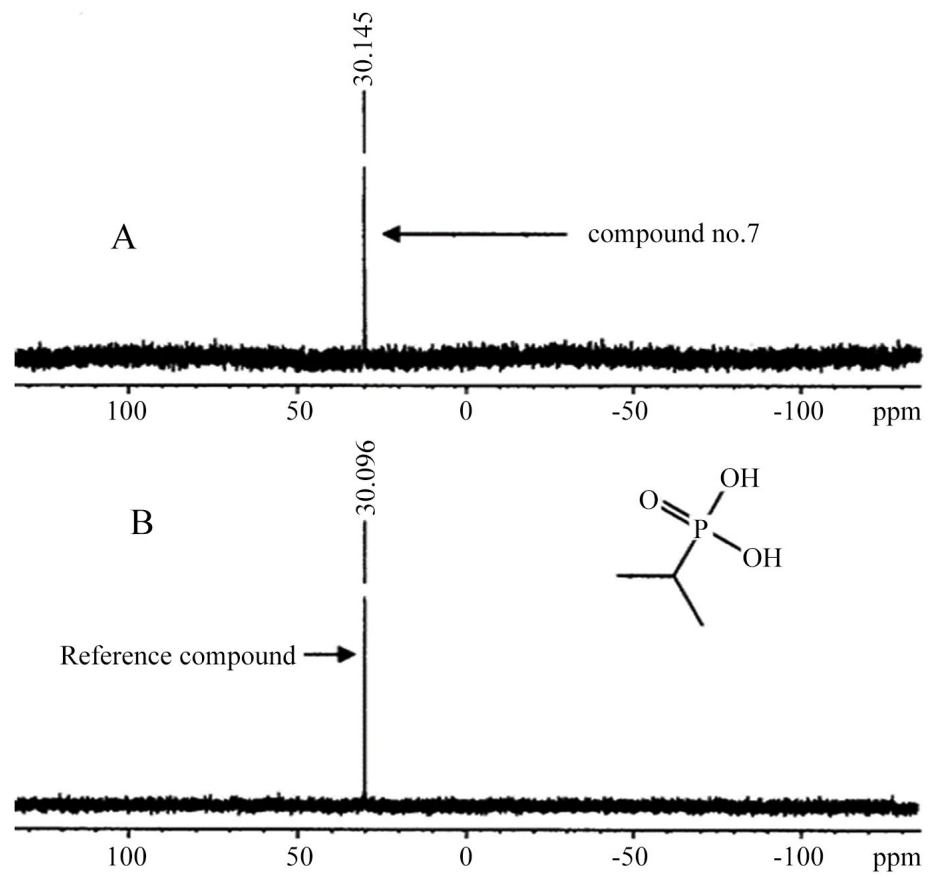

Figure 8. ${ }^{31} \mathrm{P}\left\{{ }^{1} \mathrm{H}\right\}$ NMR Spectra of Water Sample 2 (A), Reference Chemical Isopropylphosphonic acid (B). 


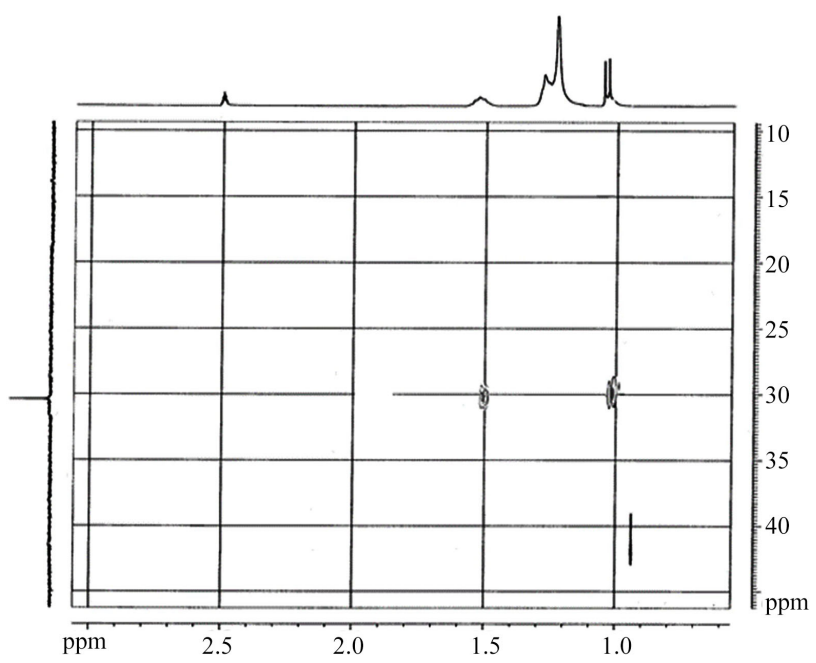

Figure 9. 2D ${ }^{1} \mathrm{H}_{-}{ }^{31} \mathrm{P}\left\{{ }^{1} \mathrm{H}\right\}$ HSQC Spectrum of Water -2 Sample showing cross peaks for Isopropylphosphonic acid.

\section{Result of Nineteenth Official Proficiency Test}

The results obtained from OPCW [45] showed that three organophosphorus compounds 4-methylpentyl methylphosphonofluoridate, 2-isopropyl 1,3,2-dioxa-phosphophinone-2-oxide, dipinacolyl dimethyl pyrophosphonate in organic liquid, four organophosphorus compounds methylphosphonic acid, pinacolyl methylphosphonate, 1-methylpentyl methylphosphonate, 4-methylpentyl methylphosphonate in water sample (W-1) and one organophosphorus chemical isopropylphosphonic acid in water sample (W-2) were spiked. Due to the non-availability of required spectra of pyrophosphonate and phosphophinone oxide, we could not identify these two compounds and missed. This indicated that the development and strengthening of in-house library of chemicals is extremely necessary for successful performance in these tests.

As our research was focused to develop the new, effective and fast $1 \mathrm{D}$ and $2 \mathrm{D}$ NMR techniques for the structure determination of CWC related compounds at trace level in mixtures of environmental samples in the field of NMR, hence we tried to perform the post analysis of missed compounds by NMR to find out the causes of misinterpretation.

\subsection{Post Test Analysis of Samples of $19^{\text {th }}$ OPTs}

\section{Organic Liquid}

2-Isopropyl 1,3,2-dioxaphosphophinone-2-oxide and dipinacolyldimethyl pyrophosphonate were synthesized in our laboratory and ${ }^{31} \mathrm{P}\left\{{ }^{1} \mathrm{H}\right\}$ NMR analysis was done, which showed chemical shift values at $33.60 \mathrm{ppm}$ and $21.48 \mathrm{ppm}$ in $\mathrm{CDCl}_{3}$ respectively. Dipinacolyldimethyl pyro-phosphonate showed twelve signals of diastereomers as shown in Figure 10, (with expansion) due to four chiral centers. After characterization, we did in-house exercise by making 10 ppm solution of pyro compound. Its sensitivity and signal intensity further gone down 10 to 12 times at $10 \mathrm{ppm}$ level. Hence pyro phosphonates with more than 


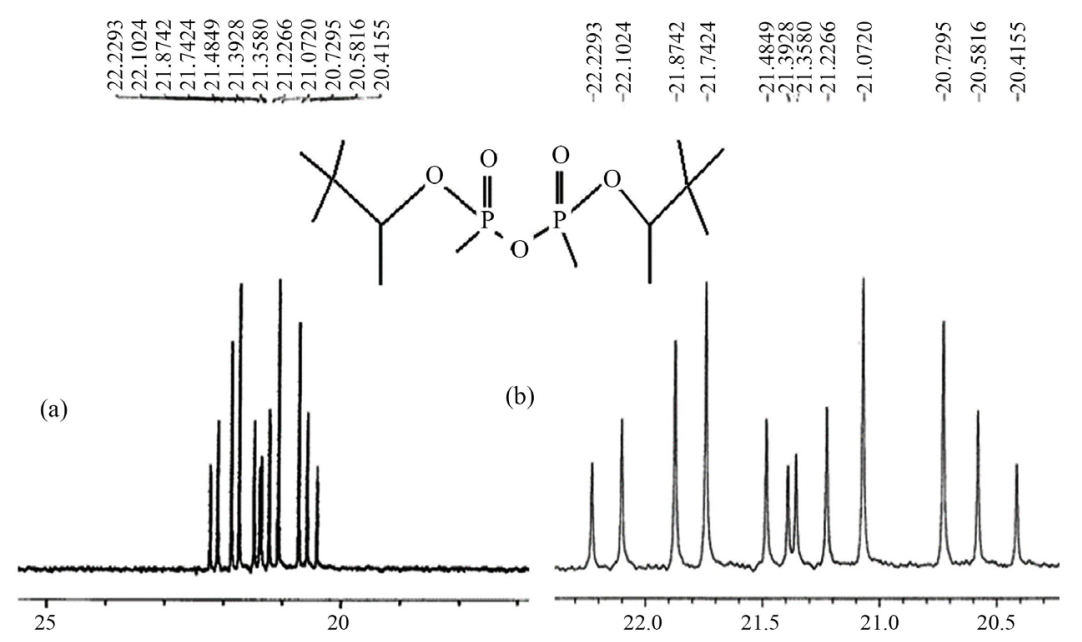

Figure 10. ${ }^{31} \mathrm{P}\left\{{ }^{1} \mathrm{H}\right\}$ NMR Spectrum of Dipinacolyl dimethylpyrophosphonate (a), and its Expanded spectrum (b) in $\mathrm{CDCl}_{3}$.

two stereogenic centers with multiple low intense signals create hurdle in identification in trace level analysis. This was the reason of getting multiple signals of low intensity of ${ }^{31} \mathrm{P}\left\{{ }^{1} \mathrm{H}\right\}$ signals in the test sample. Hence it can be deduced that identification of multiple signals of Pyrophosphonates using NMR is very difficult. The chemical shift value of synthesized 2-isopropyl 1-dioxaphosphophinone-2-oxide at $33.60 \mathrm{ppm}$ matched with spiked sample but it created confusion with Chemical shift value of Pinacolyl methylphosphonate at $33.2 \mathrm{ppm}$ in $\mathrm{CDCl}_{3}$. The dipinacolyldimethyl pyrophosphonate gave pinacolyl methylphosphonate after degradation in sample or it may get degraded in GC column used in GC/MS, which was actually obtained in our analysis at $29 \mathrm{ppm}$ in NMR and also in GC/MS analysis. So in this organic sample we reported one chemical pinacolyl methylphosphonate wrongly and missed 2-isopropyl 1,3,2-dioxa-phospho-phinone-2-oxide, and dipinacolyldimethyl pyrophosphonate in reporting due to insufficient data. Only one compound 4-methylpentyl methylphosphonofluoridate was reported correctly in organic liquid.

\section{Water 1 sample}

Among the four signals, one broad signal at $20.88 \mathrm{ppm}$ was little confusing as in this range phosphoramidates fall but in the $\mathrm{CDCl}_{3}$ solvent. During analysis this signal was missed and not reported. Later this signal was assigned for methylphosphonic acid in OPCW result. Methylphosphonic acid showed signal at $20.19 \mathrm{ppm}$ ( $\mathrm{pH} 14$, conc. $10 \mathrm{mg} / \mathrm{ml}$ ), and $30.15 \mathrm{ppm}\left(\mathrm{pH} 1,50 \mathrm{mg} / \mathrm{ml}\right.$ ) in $\mathrm{D}_{2} \mathrm{O}$ and at $26.4 \mathrm{ppm} / 31.03 \mathrm{ppm}$ in $\mathrm{DMSO}$ and $\mathrm{CDCl}_{3}$ solvent $(40 \mathrm{mg} / \mathrm{ml})$ respectively. $\delta$ (Chemical shift) at $25.12 \mathrm{ppm}$ at neutral $\mathrm{pH}$ in $\mathrm{D}_{2} \mathrm{O}$ and $28.29 \mathrm{ppm}$ in $\mathrm{CD}_{3} \mathrm{OD}$ is also observed. Water 1 sample at neutral $\mathrm{pH}$ showed signal at 20.88 ppm, while methylphosphonic acid shows signal at this ppm at $\mathrm{pH} 14$. This created confusion. Series of experiments were carried out in post sample analysis to understand the trend of $\delta$ with variation in concentration and $\mathrm{pH}$. Concentration was changed from 10,000 $\mathrm{ppm}$ to $10 \mathrm{ppm}$, likewise $\mathrm{pH}$ changed from acidic 
to basic and phosphorus chemical shift was observed which is shown in the Figure 12. In this regard, a 10,000 ppm methylphosphonic acid solution was prepared at acidic $\mathrm{pH}$ which showed signal at $\delta 30.13 \mathrm{ppm}$, while at $1000 \mathrm{ppm}$ showed signal at $27.411 \mathrm{ppm}$, after neutralization signal shifted to $\delta 25.23 \mathrm{ppm}$. However, when $1000 \mathrm{ppm}$ solution was diluted ten times, i.e., at $100 \mathrm{ppm}$, NMR signal observed at $\delta 24.331 \mathrm{ppm}$ because of dilution effect. This solution was not neutralized but it showed neutral $\mathrm{pH}$. Now this was further diluted ten times (10 $\mathrm{ppm}$ ) and showed signal at $\delta 20.751 \mathrm{ppm}$. This shows that phosphorus acids on dilution exhibit $\mathrm{pH}$ near to neutral $(6-7)$. This further confirms that there is a significant role of concentration, $\mathrm{pH}$ on chemical shift value of phosphorus acids, which is $\sim 10 \mathrm{ppm}$. Low concentration was the reason of same chemical shift value of $20.88 \mathrm{ppm}$ of MPA at neutral (low concentration) and basic $\mathrm{pH}$ (high concentration). The solvent and concentration effect on phosphorus chemical shift value is shown in Figure 11 and Figure 12 respectively.
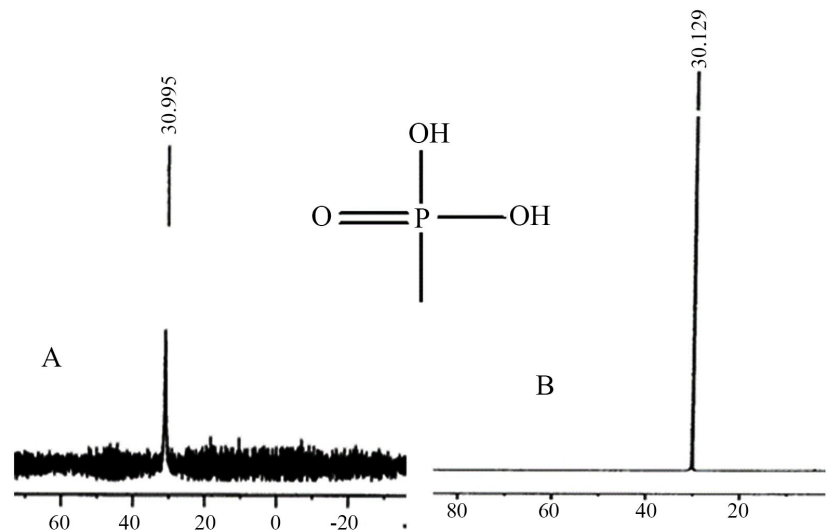

Figure 11. ${ }^{31} \mathrm{P}\left\{{ }^{1} \mathrm{H}\right\}$ NMR Spectra of Methylphosphonic acid in $\mathrm{CDCl}_{3}$ (A) and in $\mathrm{D}_{2} \mathrm{O}$ (B) showing solvent effect on chemical shift.

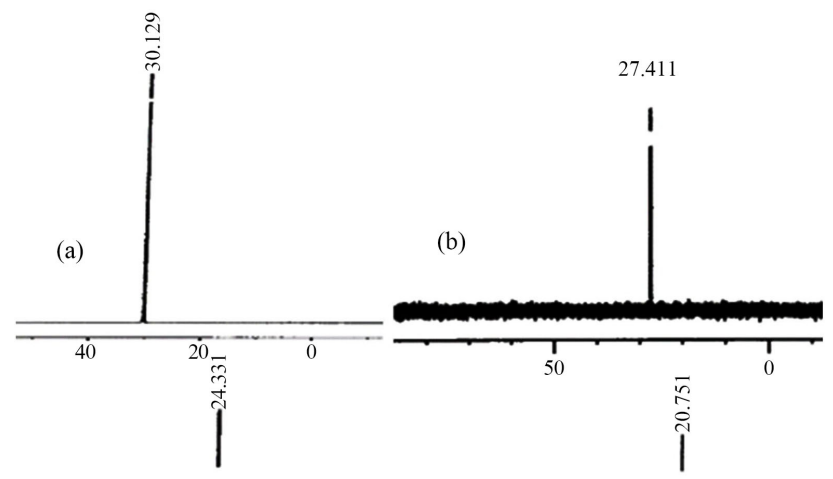

(c)

(d)

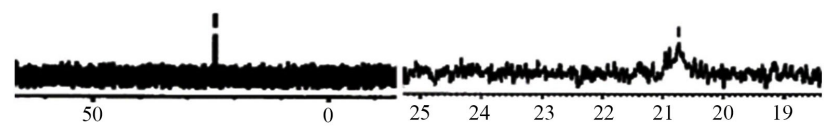

Figure 12. ${ }^{31} \mathrm{P}\left\{{ }^{1} \mathrm{H}\right\}$ Spectra of Methylphosphonic acid in $\mathrm{D}_{2} \mathrm{O}$ at 10,000 ppm after one scan (a), 1000 ppm after one scan (b), 100 ppm after one scan (c) and at $10 \mathrm{ppm}$ (d) scanned after 10,000 scans. 


\section{Conclusions}

Development of efficient procedures for retrospective detection and identification of chemical warfare agents (CWAs) and related compounds is a prime requirement for regulation of strict verification program of Chemical Weapons Convention (CWC). The expertise gained by participation in OPTs, our lab got the status of designated laboratory by OPCW. Furthermore, this is essentially required for the country, to identity the compounds and to prove unequivocally the use, to the world body, in case, of any CW agent attack by terrorists or use of agent by adversaries in the battle field. The results are acceptable to world body only, when laboratory is accredited by a national/International body and designated by the OPCW.

During the analysis of $19^{\text {th }}$ test sample it was also realized that there is difficulty in deciphering the right structure of pyro phosphonates at trace level in mixture with huge background, by NMR. Phosphorus Signal intensity of diasteromers get reduced several times due to multiple signals and low trace level, make identification further more difficult. This post analysis would help to understand the effect of chemicals, effect of $\mathrm{pH}$, concentration and effect of solution mixture on NMR Chemical shift, splitting pattern and provide direction for identification of compounds in OPTs. Further this analysis would decide the road map for identification of compounds in mixtures.

\section{Acknowledgements}

Thanks to Director, DRDE, for providing all type of supports for carrying out the NMR analysis.

\section{Conflicts of Interest}

The author declares no conflicts of interest regarding the publication of this paper.

\section{References}

[1] Convention on the Prohibition of the Development, Production, Stockpiling and Use of Chemical Weapons and Their Destruction, Signed in Paris in January 1993. Printed and distributed by the Provisional Technical Secretariat for the Preparatory Commission for the Organisation of the Prohibition of Chemical Weapons (OPCW/PTS). Depository of this Convention is the Secretary-General of the United Nations. Technical Secretariat of the Organization for Prohibition of Chemical Weapons. The Hague, 1997. http://www.opcw.org

[2] Krutzsch, W., Myjer, E. and Trapp, R. (2014) The Chemical Weapons Convention: A Commentary (Oxford Commentaries on International Law). Oxford University Press, Oxford, 768 p.

[3] Casey-Maslen, S. and Vestner, T. (2019) A Guide to International Disarmament Law. Routledge, London, 276 p. https://doi.org/10.4324/9781351108119

[4] Rautio, M. (1994) Interlaboratory Comparison Test Coordinated by the Provisional Technical Secretariat for the Preparatory Commission for the Organisation for the Prohibition of Chemical Weapons, H.1. First Interlaboratory Comparison Test. The 
Ministry for Foreign Affairs of Finland, Helsinki.

[5] Andersson, G. (1986) Analysis of Two Chemical Weapons Samples from the Iran-Iraq War. NBC Defence and Technology International, 1, 62-65.

[6] Benschop, H.P. and De Jong, L.P.A. (1988) Nerve Agent Stereoisomers: Analysis, Isolation and Toxicology. Accounts of Chemical Research, 21, 368-374. https://doi.org/10.1021/ar00154a003

[7] Koehler, K.F., Zaddach, H., Kuntsevich, A.D., Chervin, I.I. and Kostyanovsky, R.G. (1993) Absolute Configuration of Somane. Russian Chemical Bulletin, 42, 1611-1612. https://doi.org/10.1007/BF00699210

[8] Ratio, M.F. (1990) International Inter-Laboratory Comparison (Round-Robin) Test for the Verification of Chemical Disarmament. F.1. Testing of Existing Procedures. 1990; F.2. Testing of Procedures on Simulated Industry Samples, 1991; F.3. Testing of Procedures on Simulated Military Facility Samples, 1992; F.4. Validation of Procedures for Water and Soil Samples, 1993. The Ministry for Foreign Affairs of Finland, Helsinki.

[9] Mesilaakso, M. (2005) Chemical Weapons Convention Chemicals Analysis: Sample Collection, Preparation and Analytical Methods. John Wiley \& Sons, Ltd., Hoboken, 431 p. https://doi.org/10.1002/0470012285

[10] Work Instructions for the Preparation of Test Samples for OPCW Proficiency Tests, QDOC/LAB/WI/PT2, 17 September 2004.

[11] Work Instructions for the Evaluation of Results of OPCW Proficiency Tests, QDOC/LAB/WI/PT3, 15 September 2006.

[12] Rautio, M., (1993) Recommended Operating Procedures for Sampling and Analysis in the Verification of Chemical Disarmament. Ministry for Foreign Affairs of Finland, Helsinki.

[13] Standard Operating Procedure for the Organization of OPCW Proficiency Tests, QDOC/LAB/SOP/PT1, 17 September 2004.

[14] Weimaster, J.F., Beaudry, W.T., Bossle, P.C., Ellzy, M.W., Janes, L.G., Johnson, D.W., Lochner, J.M., Pleva, S.G., Reeder, J.H., Rohrbaugh, D.K., Rosso, T.E., Szafraniec, L.J., Szafraniec, L.L., Albro, T.G., Creasy, W.R., Stuff, J.R., Smith, P.B. and Stewart, I.R. (1995) Chemical Analysis of Environmental Samples Collected in Iraq: Analysis for the Presence of Chemical Warfare Agents. Journal of Chemical Technology \& Biotechnology, 64, 115-128. https://doi.org/10.1002/jctb.280640203

[15] Hooijschuur, E.W.J., Kientz, C.E. and Th Brinkman, U.A. (2001) Application of Microcolumn Liquid Chromatography and Capillary Electrophoresis with Flame Photometric Detection for the Screening of Degradation Products of Chemical Warfare Agents in Water and Soil. Journal of Chromatography A, 928, 187-199. https://doi.org/10.1016/S0021-9673(01)01133-5

[16] Hooijschuur, E.W.J., Kientz, C.E., Th Brinkman, U.A. (2002) Analytical Separation Techniques for the Determination of Chemical Warfare Agents. Journal of Chromatography A, 982, 177-200. https://doi.org/10.1016/S0021-9673(02)01426-7

[17] Black, R.M. and Muir, B. (2003) Derivatisation Reactions in the Chromatographic Analysis of Chemical Warfare Agents and Their Degradation Products. Journal of Chromatography A, 1000, 253-281. https://doi.org/10.1016/S0021-9673(03)00183-3

[18] D’Agostino, P.A., Hancock, J.R. and Chenier, C.L. (2003) Mass Spectrometric Analysis of Chemical Warfare Agents and Their Degradation Products in Soil and Synthetic Samples. European Journal of Mass Spectrometry, 9, 609-618. https://doi.org/10.1255/ejms.583 
[19] Rohrbaugh, D.K. and Sarver, E.W. (1998) Detection of Alkyl Methylphosphonic Acids in Complex Matrices by Gas Chromatography-Tandem Mass Spectrometry. Journal of Chromatography A, 809, 141-150. https://doi.org/10.1016/S0021-9673(98)00184-8

[20] Korhammer, S.A. and Bernreuther, A. (1996) Hyphenation of High-Performance Liquid Chromatography (HPLC) and Other Chromatographic Techniques (SFC, GPC, GC, CE) with Nuclear Magnetic Resonance (NMR): A Review. Fresenius Journal of Analytical Chemistry, 354, 131-135. https://doi.org/10.1007/PL00012706

[21] Wils, E.R.J., Hulst, A.G., Verwiel, P.E.J., Van Krimpen, S.H. and Niederhauser, A. (1992) Identification of an Octyl Methylphosphonofluoridate Mixture in Chemical Industry Samples. Fresenius' Journal of Analytical Chemistry, 343, 297-303. https://doi.org/10.1007/BF00322378

[22] Albaret, C., Loeillet, D., Auge, P. and Fortier, P.L. (1997) Application of Two-Dimensional ${ }^{1} \mathrm{H}_{-}{ }^{31} \mathrm{P}$ Inverse NMR Spectroscopy to the Detection of Trace Amounts of Organophosphorus Compounds Related to the Chemical Weapons Convention. Analytical Chemistry, 69, 2694-2700. https://doi.org/10.1021/ac9700639

[23] Mesilaakso, M.T. (1997) Application of NMR Spectroscopy to Environmental Analysis: Detection of Trace Amounts of Chemical Warfare Agents and Related Compounds in Organic Extract, Water, and Sand. Environmental Science \& Technology, 31, 518-522. https://doi.org/10.1021/es960352z

[24] Mesilaakso, M. and Tolppa, E-L. (1996) Detection of Trace Amounts of Chemical Warfare Agents and Related Compounds in Rubber, Paint, and Soil Samples by ${ }^{1} \mathrm{H}$ and ${ }^{31} \mathrm{P}\left\{{ }^{1} \mathrm{H}\right\}$ NMR Spectroscopy. Analytical Chemistry, 68, 2313-2318. https://doi.org/10.1021/ac960085f

[25] Mesilaakso, M. (1996) Analysis of the ${ }^{1} \mathrm{H}$ and ${ }^{13} \mathrm{C}\left\{{ }^{1} \mathrm{H}\right\}$ NMR Spectral Parameters of the Tear Gases $\alpha$-Chloroacetophenone, Dibenz $[b, f][1,4]$ Oxazepine, and 2 Chlorobenzylidene Malononitrile. Magnetic Resonance in Chemistry, 34, 989-994. https://doi.org/10.1002/(SICI)1097-458X(199612)34:12\%3C989::AID-OMR5\%3E3.0 .CO;2-E

[26] Wils, E.R.J. (2005) Gas Chromatography/Mass Spectrometry in Analysis of Chemicals Relevant to the Chemicals Weapons Convention. In: Mesilaakso, M., Ed., Chemical Weapons Convention Chemicals Analysis: Sample Collection, Preparation and Analytical Methods, John Wiley \& Sons, Ltd., 249-281. https://doi.org/10.1002/0470012285.ch11

[27] Black, R.M. and Harrison, J.M. (1996) The Chemistry of Organophosphorus Chemical Warfare Agents. In: Hartley, F.R., Ed., The Chemistry of Organophosphorus Compounds, Ter- and Quinque-Valent Phosphorus Acids and Their Derivatives (Chemistry of Functional Groups), Vol. 4, John Wiley \& Sons, Ltd., 781-840.

[28] Wils, E.R.J. (1990) Mass Spectral Data of Precursors of Chemical Warfare Agents. Fresenius Journal of Analytical Chemistry, 338, 22-27. https://doi.org/10.1007/BF00322778

[29] Durst, H.D., Mays, J.R., Ruth, J.L., Williams, B.R. and Duevel, R.V. (1998) Micro-Scale Synthesis and In-Situ Spectroscopic Characterization of Some Chemical Weapons Related Organophosphonate Compounds. Analytical Letters, 31, 1429-1444. https://doi.org/10.1080/00032719808002877

[30] Hooijschuur, E.W.J., Hulst, A.G., De Jong, A.d.L., De Reuver, L.P., Van Krimpen, S.H., Van Baar, B.L.M., Wils, E.R.J., Kientz, C.E. and Th Brinkman, U.A. (2002) Identification of Chemicals Related to the Chemical Weapons Convention during an Interla- 
boratory Proficiency Test. TrAC Trends in Analytical Chemistry, 21, 116-130. https://doi.org/10.1016/S0165-9936(01)00140-6

[31] Mesilaakso, M. and Rautio, M. (2000) Verification of Chemicals Related to the Chemical Weapons Convention. Encyclopedia of Analytical Chemistry: Applications, Theory and Instrumentation. John Wiley \& Sons, Ltd., Hoboken, 899-909. https://doi.org/10.1002/9780470027318.a0401

[32] Mesilaakso, M. and Niederhausr, A. (2000) Nuclear Magnetic Resonance in the Analysis of Chemicals Related to Chemical Weapons Convention. In: Meyers, R.A., Ed., Encyclopedia of Analytical Chemistry, John Wiley \& Sons, Ltd., Hoboken, 1026.

[33] Koskela, H. and Anđelković, B. (2017) NMR Chemical Shift and JCoupling Parameterization and Quantum Mechanical Reference Spectrum Simulation for Selected Nerve Agent Degradation Products in Aqueous Conditions. Magnetic Resonance in Chemistry, 55, 917-927. https://doi.org/10.1002/mrc.4604

[34] Koskela, H., Grigoriu, N. and Vanninen, P. (2006) Screening and Identification of Organophosphorus Compounds Related to the Chemical Weapons Convention with 1D and 2D NMR Spectroscopy. Analytical Chemistry, 78, 3715-3722. https://doi.org/10.1021/ac052148c

[35] Kostiaine, O. (2000) Chapter 11D Analysis of Chemicals Related to the Chemical Weapons Convention. In: Bogusz, M.J., Ed., Handbook of Analytical Separations, Elsevier Science, Amsterdam, 405-435. https://doi.org/10.1016/S1567-7192(00)80065-0

[36] Friebolin, H. (1993) Basic One- and Two-Dimensional NMR Spectroscopy. 2nd Edition, Wiley \& Sons, 368.

[37] Neuhaus, D. and Williamson, M.P. (2000) The Nuclear Overhauser Effect in Structural and Conformational Analysis. 2nd Edition, Wiley-VCH, Weinheim.

[38] Braun, S., Kalinowski, H.-O. and Berger, S. (1998) 150 and More Basic NMR Experiments: A Practical Course. 2nd Edition, Wiley-VCH, Weinheim.

[39] Mason, J. (1987) Multinuclear NMR. Plenum Press, Springer, Berlin, 614 p. https://doi.org/10.1007/978-1-4613-1783-8

[40] Martin, M.L., Delpuech, J.J. and Martin, G.J. (1980) Practical NMR Spectroscopy. Heyden \& Son, London, $182 \mathrm{p}$.

[41] Sharma, M., Gupta, A.K., Mewar, S., Beldar, A., Suryanarayana, M.V.S. and Raza, S.K. (2009) Direct Detection of Alkylphosphonic Acids in Environmental Matrices by Proton Coupled Phosphorus NMR. Magnetic Resonance in Chemistry, 47, 478-487. https://doi.org/10.1002/mrc.2415

[42] Koskela, H. (2010) Use of NMR Techniques for Toxic Organophosphorus Compound Profiling. Journal of Chromatography B, 878, 1365-1381. https://doi.org/10.1016/j.jchromb.2009.10.030

[43] Standard Operating Procedures (SOP) for Evaluation of Results of OPCW Proficiency Test S/46/98, Dated 21 April, 1998.

[44] Central OPCW Analytical Database. Ver. 6, Released September 2004 (Technical Secretariat of OPCW: The Hague)

[45] OPCW Verification Summary, Evaluation of Results. 19th Official Proficiency Test, OPCW Verification Division, July 2006. 